\title{
Risk of farmland degradation induced by traffic of tracked and a tired vehicles: Soil stress measurements and model simulations
}

\author{
Ding Zhao ${ }^{1}$, Lars J. Munkholm², Loraine ten Damme², and Mathieu Lamandé ${ }^{2}$ \\ ${ }^{1}$ Jinhua Polytechnic \\ ${ }^{2}$ Aarhus Universitet
}

January 30, 2021

\begin{abstract}
Vehicle traffic induced soil compaction has negative effects on soil functions and ecosystems which may cause the degradation of farmland. This study investigated the magnitude and distribution of soil stress under the tracked and tired vehicles to explore the penitential of using rubber track instead of tire to reduce the subsoil compaction. The field experiment in this study included three replicates and was conducted on a sandy loam soil. Vertical and horizontal soil stress were measured under the centerlines of the rubber track and tire at a depth of $0.35 \mathrm{~m}$ by using embedded transducers. The SoilFlex model was applied to simulate vertical and horizontal stress in the soil profile. Unevenly distributed vertical and horizontal stress were observed under the tire and rubber track. The vertical stress was characterized by one peak under the tire and several peaks under each of track wheels and rollers. The horizontal stress exhibited peaks before and after the tire and each of track wheels and rollers. The measured maximum stress was significantly higher under the tire than under the rubber track: that is, vertical and horizontal stress were approximately 3.4 and 2.0 times higher, respectively. This finding indicated that using rubber track maybe an effective method to reduce soil stress when compared with the tire, and was more effective in reducing the vertical stress than horizontal stress. Improving the uniformity of stress distribution under the track is the key to improve the ability of tracked vehicle to mitigate soil compaction.
\end{abstract}

\section{Hosted file}

Manuscript.pdf available at https://authorea.com/users/392704/articles/506475-risk-offarmland-degradation-induced-by-traffic-of-tracked-and-a-tired-vehicles-soil-stressmeasurements-and-model-simulations 

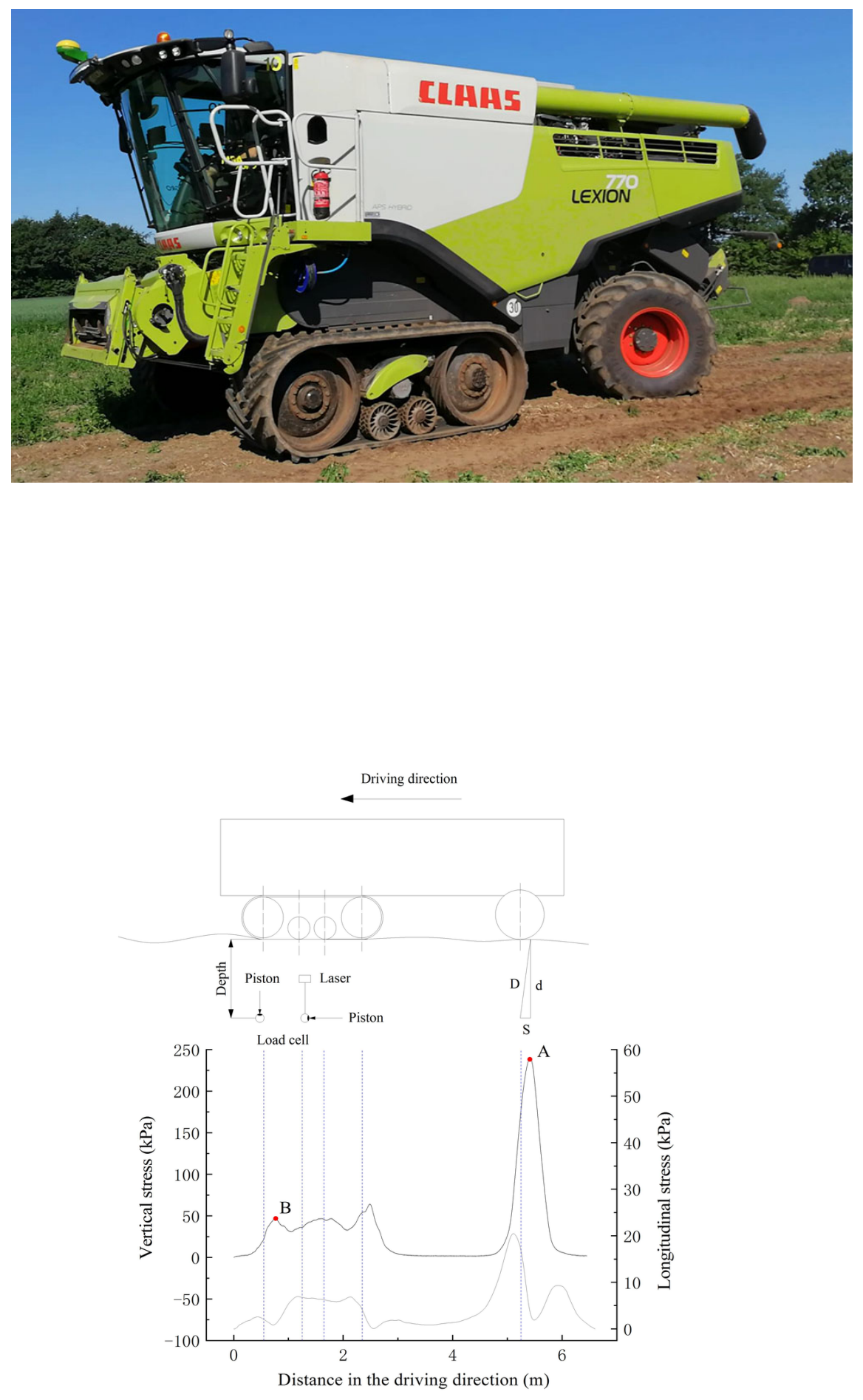
(a)

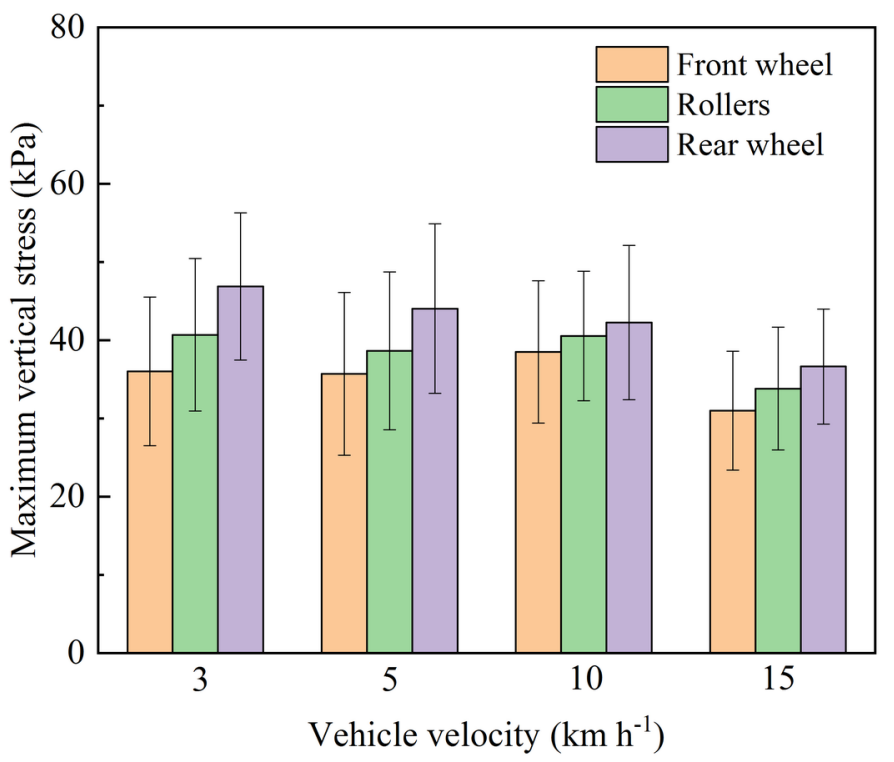

(b)

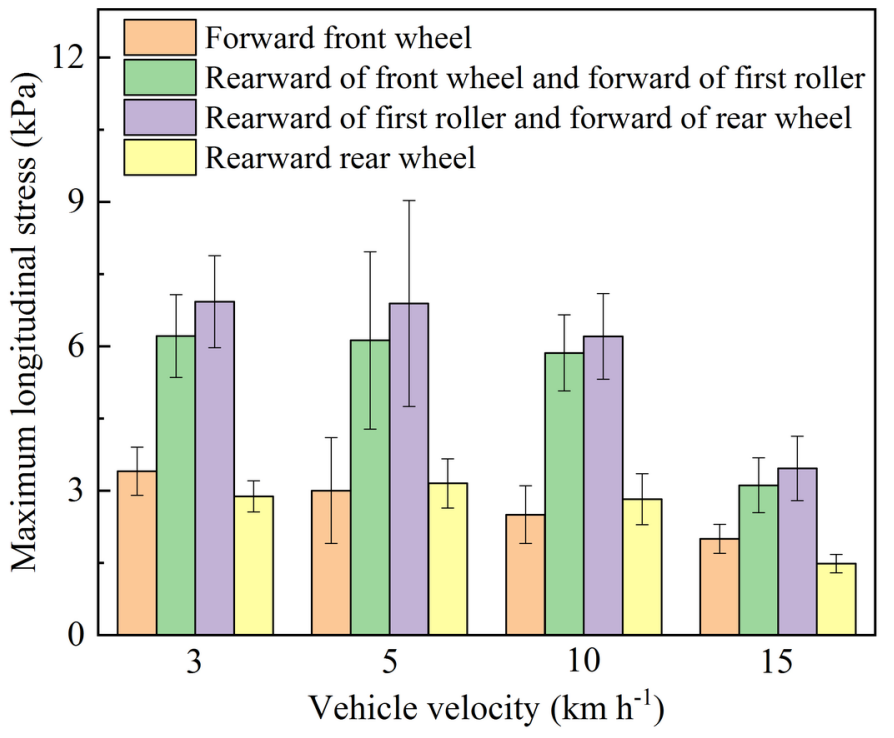


(a)

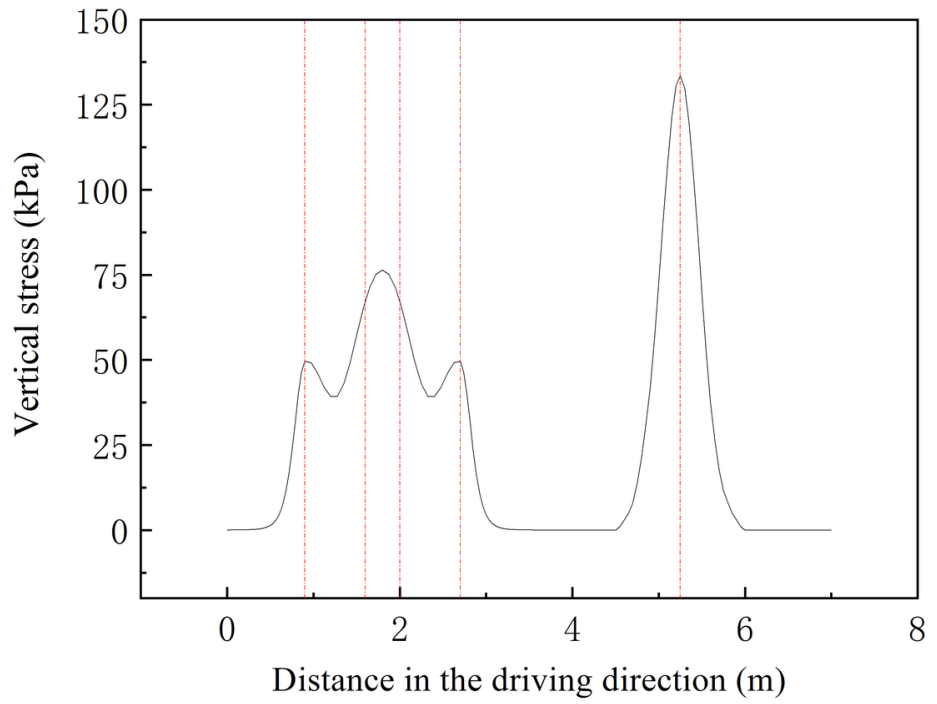

(b)

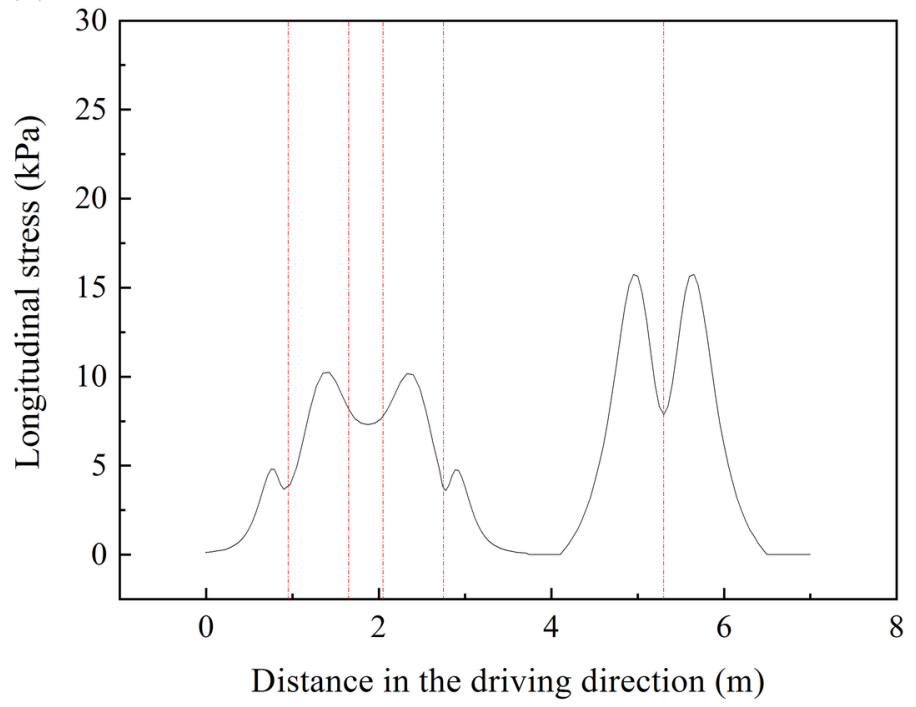



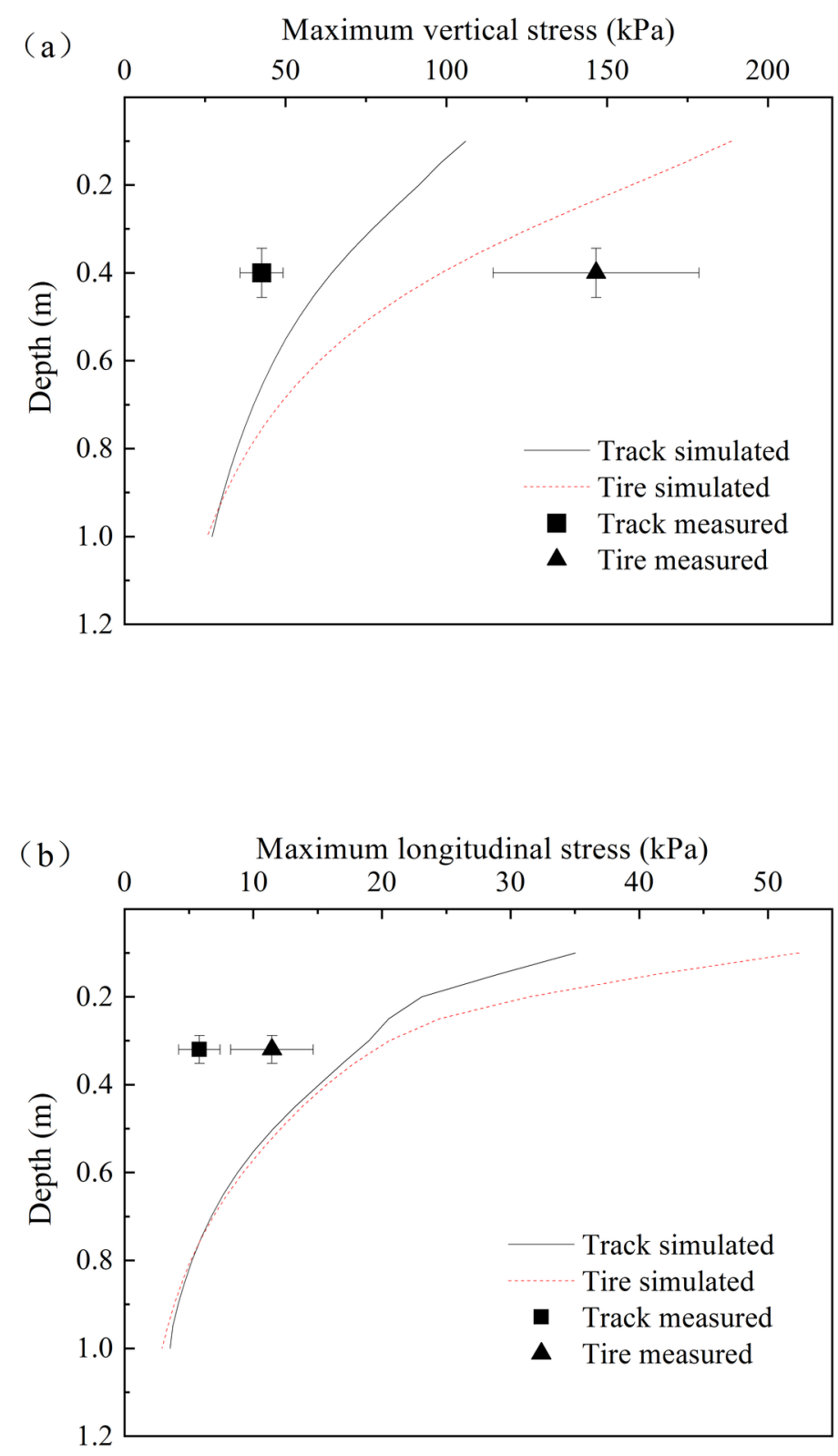